\title{
Differentiated quality assurance for the African Virtual University's teacher education qualification in mathematics and science
}

\author{
A. Hattingh \\ Joint Centre for Mathematics, Science and Technology Education \\ Department of Curriculum Studies \\ University of Pretoria \\ e-mail: annemarie.hattingh@up.ac.za
}

\begin{abstract}
For the African Virtual University and its consortium of African universities the implementation of quality promoting initiatives are not without challenges and scepticisms. To be discussed in this article is the case of a teacher education qualification in ten different African countries. Seven countries were sampled and visited in 2006 with the aim of understanding quality assurance cultures and practices used for promoting quality. Findings showed that quality assurance processes manifest at various levels of readiness and maturity. The uneven quality assurance landscape led me to propose a ten-tiered differentiated Quality Assurance Framework. In analogy to Vygotsky's theory of the 'zone of feasible development' I suggest the presence of do-able next steps where an institution can set their own priorities and timelines for reform towards quality. Self-paced planning I contend, will not be branded as technobureaucratic control, but will serve a developmental purpose towards inculcation and ownership of quality milestones.
\end{abstract}

\section{INTRODUCTION}

Quality assurance had become an essential function of higher education institutions, alongside the other core functions of research, teaching and community service (Adekanmbi 2007, 2-10; Mostert 2007, 3). Demands for accountability, efficiency and effectiveness have become paramount and clients, funders, taxpayers and governments alike need certainty with regard to the quality and value added to society by the higher education sector (Segers and Dochy 1996, 115-136; Gouws and Waghid 2006, 751-761; Higher Education Act of the Republic of South Africa 1997, iii).

For the African Virtual University (AVU) and its consortium of African universities providing quality learning experiences to their students is a high priority in the African higher education landscape. However, the heightening of quality consciousness and the implementation of quality promoting initiatives by the AVU are not without their complexities, scepticisms and challenges.

The case under discussion here is that of an African developed teacher education study programme in mathematics an science that will be delivered through open, distance and e-learning methodologies (ODeL) by the AVU and its twelve partner 
institutions in ten African countries, commencing in 2008. One of the core processes in the development of the teacher education study programme was the design of a Quality Assurance Framework that could enhance the quality of the intended programme from the initial conceptualization stage through to implementation thereof. To enable the design of a useful Quality Assurance Framework it was necessary for the AVU to commission research into the current higher education landscapes and quality assurance practices of the chosen countries and institutions in which the programme would be operating.

Consequently and through this paper, the aim is to provide insight into the current higher education and quality assurance landscapes of the chosen countries and higher education institutions in which the programme will be implemented. To provide the overview I have developed a ten-tiered differentiated findings framework based on an acknowledgement of heterogeneous local contexts and different higher education landscapes. This article concludes by suggesting how that framework may be used by institutions as a self-developmental tool in the planning and formalisation of an institutional quality assurance culture. The differentiated framework may well serve as a conceptual frame for a Quality Assurance Framework to be adopted by the AVU and its partners. The aim of this paper is not to provide the extended Quality Assurance Framework, as this has been done elsewhere (see Hattingh, 2007).

\section{RELEVANT THEORETICAL QUALITY ASSURANCE CONCEPTS}

The concepts of quality and quality assurance are not unproblematic. These concepts can have very different meanings and interpretations to both the providers of quality as well as the consumers of quality. In the quality assurance discourse, as is currently the case in South Africa for example, quality assurance is viewed as a process of programme and institutional 'accreditation' (Gouws and Waghid 2007, 751). Initially quality assurance gained currency in South Africa by the South African Universities' Vice-Chancellors Association in 1995 and began with a developmental focus in mind. This focus gradually dissipated and it is warned that quality assurance may become a 'technobureaucratic' exercise characterized by a checklist mentality, window-dressing and external policing (Gouws and Waghid 2007, 752). In addition, there seems to be a concern about the integrity and validity of those who have to assure and accredit the quality. Put differently, 'who will guard the guards?' (Gouws and Waghid 2007, 754) as quality assurance may be manipulated and open to abuse (Alderman and Stephenson 2005, 326).

However, for the purpose of this research, quality assurance is situated in the conceptual frame of programme and institutional development and improvement. A suitable working definition of quality that underpinned this research was selected for its inclusion of process, product and people attitude dimensions:

Quality is a product of planning, monitoring, control, and coordination ... it depends on products, processes, systems and people ... Quality assurance does not merely 
mean a set of procedures to be followed - it is also an attitude or ethos which influences every aspect in an organization's activity (Robinson 1993, 77, 79).

This definition alludes to the fact that a commitment to quality ought to form part of an institution's culture.

A description of quality assurance for the purpose of this research will better be understood in terms of a rationale which is the following: informed by a need to protect learners from inferior and non-relevant education; determine the level at which provision and the depth of learning is acceptable with regard to open, distance and e-learning higher education environments; determine the fitness for purpose and the progress in moving towards national, institutional and programme goals and mission; identify problem areas and action plans for addressing these and finally contribute towards the inculcation of an institution's culture of quality.

\section{BACKGROUND TO THE AFRICAN VIRTUAL UNIVERSITY CASE OF A MULTI-COUNTRY TEACHER EDUCATION QUALIFICATION}

The two sections that follow briefly sketch the case of the African Virtual University and the intended teacher education study programme.

\section{The genesis of the African Virtual University}

The AVU was established in 1997, as a project of the World Bank, with its headquarters in Nairobi, Kenya. It is not a university in the traditional sense of the word. When it was initially established the AVU brokered content and qualifications from reputable institutions abroad. (This was seen as a cost effective way to pass world class content on to large numbers of African students through various forms of media, one of which was asynchronistic video conferencing.) The focus of the AVU now is to be part of a network that works with and supports other universities in Africa through open, distance and electronic (ODeL) methodologies geared towards enhancing thinking and delivery around mixed, distributed and blended forms of teaching and learning. A main challenge for the AVU was that all previous programme development did not include academics, policy-makers, tutors and managers from African institutions (Dzvimbo and Kariuki 2006, 19). The intended teacher education study programme at stake here faced this challenge head-on, as the curriculum, electronic materials and the Quality Assurance Framework are designed and owned by African academics who worked with selected ICT instructional designer specialists from abroad.

\section{The teacher education study programme - background and challenges for assuring quality}

Particularly in Sub-Saharan Africa, two problems of teacher supply that threaten the attainment of continental education targets are noticeable. First, is the shortage of teachers, occasioned by increasing numbers of pupil enrolments and the negative 
impact of the HIV/AIDS pandemic; second, is that even where there are enough teachers, many of them are un- or under-qualified and the quality of teacher education itself is often inadequate. As part of its strategic responses to the challenges facing the teaching profession on this continent, the AVU has initiated a continent-wide teacher education study programme, which focuses on increasing the quantity and quality of mathematics and science teachers, through the use of Information and Communication Technologies (ICTs) both in and across the curriculum. The current curriculum consists of 52 electronic modules and materials that were produced by African subject matter experts, ICT integration instructional designer experts and study material development coordinators. Partner institutions may select modules that can be aligned with or replace their existing teacher education study programmes from the available electronic modules 'menu' (Teacher Education Advisory Committee 2007, 9-12).

The objective of the teacher education study programme is to enhance the capacity of teachers (initial/in-service and primary/secondary) in teaching mathematics and science (biology, physics and chemistry). To achieve the above objective, the African Development Bank (AfDB) granted the AVU funds for the design, development and implementation of the programme in twelve institutions, in ten countries; namely: Senegal, Ethiopia, Kenya, Madagascar, Mozambique, Somalia, Tanzania, Uganda, Zambia and Zimbabwe. The funding made available for setting up ODeL centres at participating universities provided for internet connectivity (broad band, bandwidth), satellite dish and installation, 30 computers, 2 servers, printers, power backup generators, computer room furniture and a LCD projector. The AVU was also responsible for initial technical and end-user training.

Major challenges in a programme of this nature that confront quality assurance go far beyond the delivery mechanism; which is open, distance and e-learning. Since the programme is offered across multi sites and in multi countries, the higher education landscape within which each partner institution operates is unique to its particular country. The higher education landscape may comprise any number of the following entities: Departments of Education, Professional Bodies, Unions, Internal Institutional Quality Assurance Mechanisms and Higher Education Quality Authorities external to the universities that oversee quality and programme accreditation. Many of the partner institutions involved in this teacher education study programme already have some sort of internal quality assurance mechanism operating at different levels.

A further challenge to the implementation and quality assurance of the teacher education study programme is that it need be made available in three different languages; namely: Anglophone, Francophone and Luciphone. Furthermore, in the intended programme three distinct fields - teacher education, mathematics and science education and the ODeL delivery mode - interact to provide learning opportunities to students. Due to the unique nature and innovation in each of these three fields it is necessary the quality criteria address varied issues; these range from conceptual mental models, field specific innovations, academic, administrative, technical, governance and to logistical issues. The challenge was to locate distinctive quality indicators from 
each field and integrate these into a single feasible Quality Assurance Framework that allows for flexibility in interpretation and application by twelve universities. The intersection of the quality indicators for each of these three fields perhaps best represents the minimum standards to be taken up in the Quality Assurance Framework for this particular programme. Figure 1 graphically presents the challenge of accommodating quality criteria for each of the three programme domains:

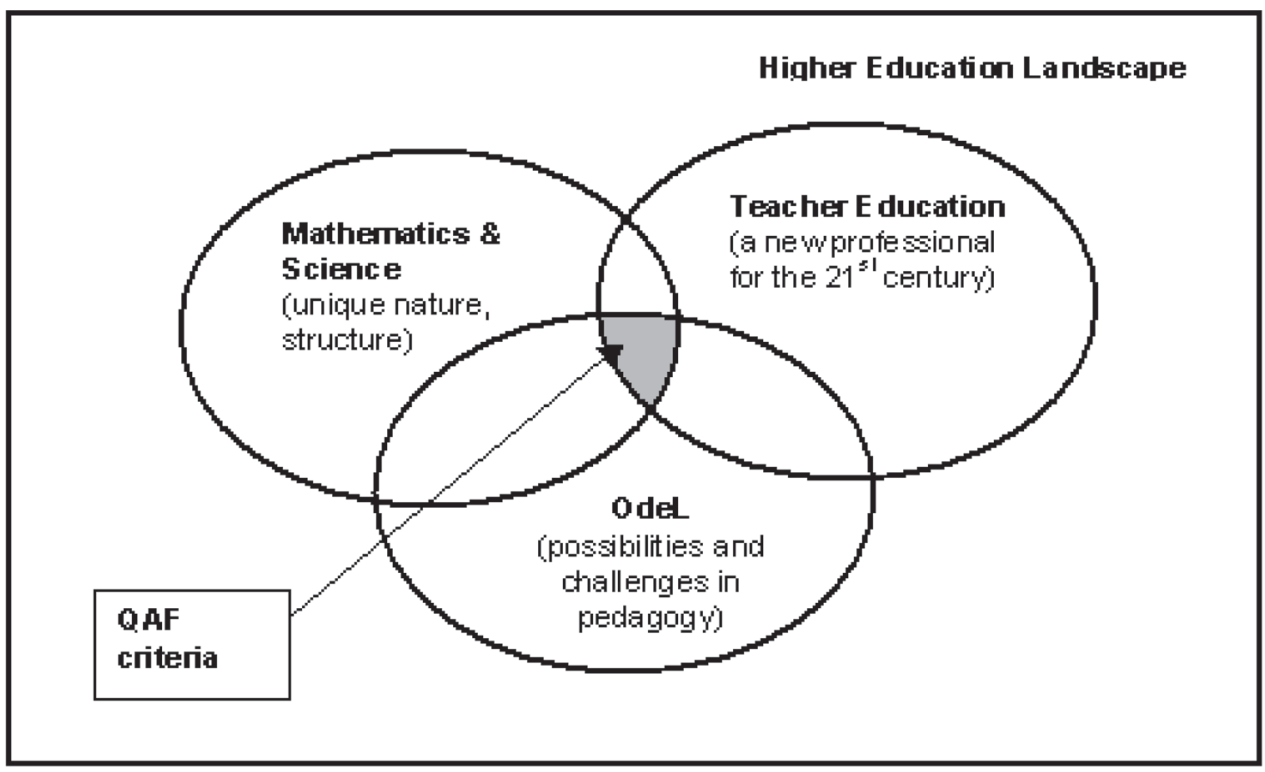

Figure 1: Intersection of three domains: Mathematics and Science, teacher education and ODeL delivery

\section{METHODOLOGICAL PATHWAY TOWARDS DEVELOPING THE QUALITY ASSURANCE FRAMEWORK}

Of the twelve universities that are involved in offering the training programme, seven universities were sampled. It was necessary to include at least one university of each language group in the sample. The Francophone university of Universite d'Antananarivo was selected due it being on the island of Madagascar, unlike the other partners that are all situated on the African continent. The seven universities were: University of Nairobi (Kikuyu Campus in a semi-rural area), Kyambogo University (Uganda), Open University of Tanzania, University of Zimbabwe, University of Zambia, Universidad Pedagogica in Mozambique (Portuguese language) and Universite d'Antananarivo (French language). Before commencing my visits to these universities, I visited the headquarters of the AVU in Nairobi, Kenya for four days. Before commencing with 
the contact visits I informed the coordinator of the teacher education study programme at each institution the individuals whom I would like to meet, to conduct interviews and discussions. Between 15 November and 24 December 2006 I spent two to three days at each sample institution, while conducting nineteen individual and ten focus group interviews. These interviews were followed up by many e-mail and telephone conversations. My field visits included meeting with principal role players; such as vice-chancellors, deans and vice-deans of faculties of education, heads of the schools of education, academic registrars, human resource managers, librarians, directors of computer centres, ODeL centre managers, technical support staff, administrative support staff, teacher educators and curriculum planning committees. The services of translators were used for communications across language barriers. I also visited the physical sites where the AVU ODeL Centre was or would be located, as well as the installation location of the satellite (Vsat).

An extensive document analysis was undertaken, where documents were provided (either through hard- or e-copies) by the AVU and partner institutions. Documents included yearbooks, regulations, marketing materials, internal and external examination and moderation reports, curricula of existing other teacher education study programmes, marketing materials, minutes of strategic planning meetings, staff training schedules and ODeL site construction or renovation plans.

\section{Validity of findings}

Probably the best level of validity was achieved when the AVU and the consortium of all twelve partner institutions met in Nairobi from 4-5 April 2007. The consortium consisted of all the deputy vice-chancellors (academic affairs) and the deans responsible for implementing the intended teacher education study programme - identified as the Teacher Education Advisory Committee. The Teacher Education Advisory Committee reports to the vice chancellors/rectors/presidents of participating universities as well as the AVU rector. At this meeting the researcher presented the research findings and proposed a Quality Assurance Framework to the Teacher Education Advisory Committee for scrutiny and adaptation. The findings were accepted on 5 April, in a document entitled the Nairobi Declaration (Teacher Education Advisory Committee 2007, 14).

\section{DISCUSSION OF FINDINGS - EARLY AND PRESENT QUALITY ASSURANCE MEASURES AND LANDSCAPES}

The findings that emerged of the quality assurance measures and landscapes gravitated in two distinct directions. First, I describe the early quality assurance measures that were designed into this teacher education study programme at its inception and, second, I report on the present quality assurance landscapes and existing processes in which the programme will operate. 


\section{Early quality assurance measures for the teacher education qualification}

The commitment to a culture of academic integrity and quality by the AVU and its partner institutions is evidenced by their ever mindful application of those processes from the initial planning of the programme to the present.

The first measure was the selection of partner institutions. Since the AfDB grant for this programme covers programme development and implementation in the 10 countries identified, it was deemed important that the AVU select one institution in each country to act as the coordinating point for the programme. The selection of creditable institutions was meticulously executed, to ensure that only those institutions that were capable of implementing the programme were selected. To this effect, terms of reference with selection criteria were carefully developed and sent to both the Ministry of Education and institutions of higher education in each country. This process ensured only institutions that 1) had a teacher education faculty that was already well established, 2) had an operating form of distance education in teacher education, 3) were the lead teacher education institution within the country, and 4) had a relatively country-wide influence in terms of satellite or regional centers in semi and deep rural areas.

A second measure revolved around the conceptualization of the curriculum and policy formulation. To ensure that the program was well conceptualized and that it addressed the needs of the countries that had to benefit from it, the AVU convened a Policy and Curriculum Conceptualization Workshop that drew participation from the Ministries of Education, Teachers Service Commissions (or their equivalent) and representatives from the selected partner institutions. To enrich the outcomes of the workshops teacher education and Open, Distance and e-Learning experts from all over the world were invited to participate. The outcomes of these workshops included the development of policies to guide the programme and a conceptualized curriculum. The policies included the prerequisite of a quality assurance framework for the programme. The collaborative process and the engagement of experts in the relevant areas ensured that the outcomes of the workshop presented programme guidelines that would ensure high quality outputs from the offset.

A third area of initial quality assurance can be related to the process of electronic module design and materials development. In line with the collaborative process approach for this programme, the AVU engaged subject matter experts from partner and other African institutions and sought top-notch ICT instructional designer education experts from all over the world to coordinate and oversee the development of the modules and materials for the programme. To ensure that the participants were of a high standard, the AVU requested the Deputy Vice Chancellors of academic affairs to select subject matter experts from their faculty members, who then represented their institutions. A rigorous process was employed in the search for ICT integration consultants. So much was the care accorded to their selection that the presentation of the curriculum design workshop was delayed by three months - due to insufficient 
numbers of appropriately qualified consultants. To ensure that the final design of the curriculum fully supported the education systems of the various countries, a decision was made to have the Francophone African countries convene a separate workshop to address their needs, as it emerged that their education system differed greatly from the Anglophone African countries. The first phase of materials authoring - for 29 of the 52 modules - commenced in August 2006. The strategy involved team work, drafting, integration of multi-media, peer review, editing; and was completed in February 2007. The content authoring for the second phase modules began in March 2007 and ended in June 2007. The actual delivery of the comprehensive ODeL teacher education study programme is planned for September 2007.

\section{Present quality assurance measures and landscapes for the teacher education study programme}

The internal institutional quality assurance cultures and mechanisms of the sampled institutions manifested at different levels of maturity and different institutions find themselves at different stages of readiness to implement the programme. For the discussion of the findings it is important to mention upfront that it was not the aim of this research to do an evaluation of the quality at the partner institutions; so care should be taken not to work from the assumption that the absence of quality assurance mechanisms at a partner institution implies that quality is absent overall.

In order to make sense of the multiple manifestations of quality assurance realities and processes, I have developed a ten-tiered differentiated findings framework (see Table 1) to analyse and describe the findings.

Table 1: Ten-tiered differentiated findings framework for different levels of quality assurance maturity

\begin{tabular}{|l|l|l|}
\hline Level & $\begin{array}{l}\text { Products and } \\
\text { processes to be } \\
\text { quality assured }\end{array}$ & $\begin{array}{l}\text { Party/mechanisms responsible for executing quality } \\
\text { assurance }\end{array}$ \\
\hline 1 & $\begin{array}{l}\text { No documented } \\
\text { policies or official } \\
\text { quality assurance } \\
\text { measures } \\
\text { implemented }\end{array}$ & $\begin{array}{l}\text { No internal or external procedures are documented for } \\
\text { curriculum, pedagogical assessment, study materials, } \\
\text { delivery, staff, student and/or management issues in } \\
\text { place. }\end{array}$ \\
\hline 2 & $\begin{array}{l}\text { Student assessments } \\
\text { and summative } \\
\text { evaluations }\end{array}$ & $\begin{array}{l}\text { - Internal examiners and moderators (from same } \\
\text { university) involved and setting and marking of exams; } \\
\text { External examiners and moderators (from other } \\
\text { universities in the same country) involved and setting } \\
\text { and marking of exams; } \\
\text { External examiners and moderators (from universities } \\
\text { in other countries) involved in assessment. }\end{array}$ \\
\hline
\end{tabular}




\begin{tabular}{|c|c|c|}
\hline 3 & $\begin{array}{l}\text { Programme design } \\
\text { and curriculum } \\
\text { development }\end{array}$ & $\begin{array}{l}\text { - New programmes and curricula approved at faculty } \\
\text { level and submitted to approval by an institution's } \\
\text { senate; } \\
\text { - External subject specialist peers (from Africa and } \\
\text { abroad) involved in the development of new } \\
\text { programmes and curricula; } \\
\text { - External subject specialist peers (from Africa } \\
\text { and abroad) involved in the assessment of new } \\
\text { programmes and curricula. }\end{array}$ \\
\hline 4 & $\begin{array}{l}\text { Instructional materials } \\
\text { and learning } \\
\text { resources }\end{array}$ & $\begin{array}{l}\text { - Materials brokered from other institutions; } \\
\text { - Academic staff develop their own instructional texts } \\
\text { (Tutorial letters, study guides and academic texts/or } \\
\text { select prescribed texts; } \\
\text { - Consortium (academic staff and peers) from other } \\
\text { institutions develop instructional texts (Tutorial letters, } \\
\text { materials and academic texts); } \\
\text { - Materials are language and technically edited; } \\
\text { - Materials are field tested; } \\
\text { - Printing quality monitored. }\end{array}$ \\
\hline 5 & $\begin{array}{l}\text { Teaching } \\
\text { Learning }\end{array}$ & $\begin{array}{l}\text { - Student feedback; } \\
\text { - Peer observations and feedback; } \\
\text { - Self-reflection and action research documented in } \\
\text { professional portfolio; } \\
\text { - Suitable opportunities exist that ensure appropriate } \\
\text { learning experiences (e.g.: practical work and school- } \\
\text { based teaching). }\end{array}$ \\
\hline 6 & $\begin{array}{l}\text { Technical, computer } \\
\text { and ODeL facilities }\end{array}$ & $\begin{array}{l}\text { Technical functioning of equipment and e-learning } \\
\text { platforms and resources are managed by suitable } \\
\text { technical staff and technical centre directors; } \\
\text { Students get the opportunity to provide formal feedback } \\
\text { about the functioning, accessibility and usefulness of } \\
\text { facilities (technical and libraries). }\end{array}$ \\
\hline 7 & $\begin{array}{l}\text { Student recruitment } \\
\text { and selection }\end{array}$ & $\begin{array}{l}\text { Face-to-face contact sessions at satellite sites or centres; } \\
\text { Face-to-face contact sessions, supported by radio/ } \\
\text { television broadcasts, newspaper columns, audio-tapes, } \\
\text { CD Roms; } \\
\text { Well trained academic tutors available at centres for } \\
\text { actual, land line telephone, cellphone, online support } \\
\text { during office hours; } \\
\text { Well trained academic tutors available at centres for } \\
\text { actual, land line telephone, cellphone, online support } \\
\text { any time a student needs it which is most likely after } \\
\text { hours when a student is studying after completing her/ } \\
\text { his day job; } \\
\text { Counselling tutors or centres exist that provide psycho- } \\
\text { social and emotional support. } \\
\text { Student recruitment and selection. }\end{array}$ \\
\hline
\end{tabular}




\begin{tabular}{|l|l|l|}
\hline 8 & Staff: & $\begin{array}{l}\text { Sufficient staff support, development and training } \\
\text { opportunities exist that ensure staff performance; } \\
\text { Students provide feedback on staff performance related } \\
\text { to student learning affairs; } \\
\text { Staff performance monitored by an internal institutional } \\
\text { performance management system; } \\
\text { Academic staff are rated by academic peers (local and } \\
\text { international). }\end{array}$ \\
\hline 9 & $\begin{array}{l}\text { Administrative } \\
\text { Technical } \\
\text { qualifications or } \\
\text { faculties and schools } \\
\text { within an institution }\end{array}$ & $\begin{array}{l}\text { An internal quality assurance unit exists that oversee } \\
\text { quality; } \\
\text { External quality assurance exist in the form of a national } \\
\text { higher education regulatory body for accreditation } \\
\text { purposes of specific qualifications; } \\
\text { Internal quality audits are conducted - panel includes } \\
\text { peers from local and international higher education } \\
\text { institutions. }\end{array}$ \\
\hline 10 & $\begin{array}{l}\text { Entire institution (All } \\
\text { faculties, services, } \\
\text { products and } \\
\text { processes) }\end{array}$ & $\begin{array}{l}\text { Systemic and holistic evaluation of an entire institution; } \\
\text { External quality assurance by a national regulatory body } \\
\text { for institutional accreditation purposes. }\end{array}$ \\
\hline
\end{tabular}

None of the levels contained in the framework are superior to any of the other levels. The levels are merely a categorization of different quality assurance manifestations, where the higher levels are indicative of more mature quality assurance landscapes and mechanisms.

Level 1 practices (no documented quality assurance): The only Francophone institution in the sample, the Universite Antananarivo (Madagascar), typically manifested on level 1 of the framework. Quality assurance measures were not explicit activities in that university. The rector of that institution welcomed the idea of a Quality Assurance Framework and requested programme and assessment evaluations together with South African as well as partner universities in the AVU consortium to commence as soon as possible. During the data validation session in Nairobi, the Deputy Vice Chancellor of Universite Cheikh Anta Diop De Dakar confirmed that Francophone universities 'do not have a tradition of regulating quality assurance mechanisms.

Level 2 (assessment) and level three (programme and curriculum design) practices: The other universities sampled - the University of Nairobi, Kyambogo University, Open University of Tanzania, University of Zimbabwe, University of Zambia and Universidad Pedagogica (Mozambique) - have level 2 and selected level 3 quality assurance practices in place. At level 2 the universities all have internal (in the same institution) and external (not from the same institution) evaluation and moderation procedures in operation, to monitor the quality and standards of exam papers and the consistency and standard of marking by internal staff. The setting and marking of exam papers was generally moderated by peers at similar institutions within the same country. None of those universities employed peers from institutions outside their own country for that purpose. A previous area of concern to cause 
many problems for the Distance Education Units was when examinations had to be administered across multiple sites, leading to the leaking of exam papers. All these universities provided extensive details on the practices that they have put in place to avoid such occurrences in future. None of the sample institutions yet employed electronic methods for summative evaluation and the general orientation regarding this was captured as follows: 'It is a high stakes, high risk exercise to administer e-assessments and the consortium will face may challenges and need to learn many lessons before online assessment can be taken to scale and taken up into the teaching policy' (Distance Education Head, Zambia). At level 3 all those institutions (also the Francophone universities) require that new or adjusted programmes need to be approved at both faculty and senate level. The other practices that are described on level 3 have not been implemented at those institutions.

Level 4 (instructional materials and resources): Most of the universities sampled require of their academic staff to develop their own instructional texts and tutorial letters. Kyambogo University (Uganda) has a 'database of instructional designers and writers who are trained as required. A curriculum committee review the writing of materials' (Future ODeL Centre director). The Universities of Zambia, Kenya and the Open University of Tanzania, have very sophisticated and fine-tuned processes assuring the quality of production (language, technical editing, design and layout), printing and timely delivery of study materials, whether paper or electronic based. The Open University of Tanzania has a dedicated, well-equipped unit with a strong leadership to oversee the production and field testing of instructional materials. Students also get opportunity to provide feedback on the quality and learnercentredness of the materials. For the intended teacher education study programme all the universities have appointed directors for the AVU ODeL centres, to be assisted by centre managers. In most cases additional technical staff have also been allocated to the AVU ODeL centres, to ensure the smooth running of the computer hard- and software. At all the partner institutions, the AVU ODeL centres were in a process of being built or upgraded. Most of the partner institutions were still awaiting the installation of the V-Satellite.

All the distance education units at those universities have, in the past, used mechanisms to obtain feedback regarding the usefulness, learner friendliness and accessibility of the learning support materials from their end users, namely the students. The feedback was reported to a programme coordinator or academic committee that would then make decisions regarding the accommodation of student comments and requests for the future.

Level 5 (teaching and learning): I did not come across processes in the distance education mode where students have the opportunity to comment or provide feedback on the learning facilitation offered by academic lecturers or other staff services. However, at four of the universities students have formal opportunities to provide feedback on face-to-face lectures offered by academic staff.

In a qualification such as the teacher education study programme, practical teaching experience in schools for pre-service teacher education is an important competency 
developing strategy to achieve the curriculum exit level outcomes. It was not clear how the pre-service practical school-based learning experiences have been organised and monitored by the academic staff in the past. Most of the distance education units at the partner institutions did not have a teaching-practice element and no assessment of this to contribute to a final mark. The intended Quality Assurance Framework for the teacher education study programme will require practical, authentic, schoolbased experiences as one of the significant learning strategies.

What was also not clear was how subjects with practical work - laboratory components such as chemistry, physics, biology and ICT - would be accommodated and monitored in the curriculum. The deputy vice-chancellors of the universities of Kyambogo and Tanzania explained during the data validation meetings that arrangements/collaborations with business, industry, schools or other suitable institutions close to the satellite sites are made to house practical work and faceto-face sessions on behalf of their institutions. They mentioned that lessons may be learnt from other programmes - such as engineering - that have included compulsory practical modules as part of their distance education study programmes.

Level 6 (technical, computer and ODeL facilities): As mentioned under past quality assurance practices, the AVU oversees the technical set-up of ODeL centres and end-user training. In addition to the traditional access to libraries, open libraries and open-resources are accessible through the online modules that will be offered in the teacher education study programme.

Level 7 (student support): Since all the universities have rich histories and experience in distance education, level 7 quality assurance processes existed that ensure different kinds of student support. All the distance education units described their student support mainly in terms of delivery, where paper-based instructional materials are supported by two to three one week face-to-face contact sessions at the satellite centres during an academic year. Certain universities - see for example Kyambogo, Zambia, Tanzania and Pedagogica - supplement face-to-face sessions with radio broadcasts, newspaper columns and audio tapes. The Kyambogo University in Uganda for example views student support beyond delivery of instructional materials. They have adopted a 'culture of care' ethos. This 'culture of care' ethos was given impetus by a five year training programme sponsored by the Nuffield Foundation, for all human resources involved in distance education. The training aimed at '... making them (staff) realise from their own experience just what learners need' as well as improving their knowledge of open and distance learning (Graham and Tierney 2003, 5). A major support intervention is the increased availability and accessibility of tutors, due to shared telephone numbers during and after hours. There is also greater understanding about the financial difficulties that students experience and how these can be accommodated. Different methods of fee payment are considered - instalments are a new addition to the payment structure. The implementation of the 'culture of care' psycho-emotional support is explained in a comprehensive article by Binns and Otto (2006). 
Level 7 (student selection): The University of Zimbabwe displayed level 7 quality assurance measures in the recruitment and selection of potential students intending to enrol for any qualification offered by the university. The academic registrar explained that students applied on a very competitive basis for acceptance into a programme, which ensures a measure of success with the completion and through-put rate of students. For the teacher education study program the AVU has launched effort and awareness aimed at mainstreaming females into the selection process. Gender awareness and policy for selection of females were not yet a priority at partner institutions.

Level 8 (staff): The rectors and deans of the sampled universities made their intentions clear that rigorous training of academic staff to be responsible for the delivery and facilitation of the online modules was a high priority on the implementation agenda. The commitment to training of human resources in online learning was also embraced and prioritised by all Deputy Vice Chancellors, as shown in the Nairobi Declaration. Agendas and minutes of departmental and faculty meetings provided evidence that stated in no unclear terms that 'the success of the programme depends on the training of academic staff to utilise and manage the online modules and materials with confidence and eventually to develop their own electronic versions of the materials' (Deputy Dean Zimbabwe). The University of Zambia and Kenya had already developed preliminary schedules for staff training in this study programme.

The other activities described on level 8 are not present at the sampled institutions. None of those universities are subject to performance management and academic staff is not rated by a peer-evaluation system.

Level 9 and level 10 (programme and qualification audit) and 10 (institutional audit): None of the partner institutions reported activities that can directly be described as level 9 and level 10 quality assurance measures. Uganda has recently established a National Council for Higher Education, located at Kyambogo University, where the possibility of official accreditation of qualifications is in the pipeline. And that might affect the future of a programme such as the intended teacher education study programme within that country. In the case of the teacher education study programme the AVU will not have the role of accrediting the programme across the partner institutions. What the AVU will need to do to ensure the quality of the teacher education study programme is to establish an actual and virtual quality assurance unit, where stakeholders from the different institutions should be represented to manage the implementation of a differentiated Quality Assurance Framework.

\section{REFLECTIVE COMMENTS AND CONCLUSION}

The above findings reveal that the quality consciousness and mechanisms of partner institutions manifest at various levels of sophistication, complexity and maturity in a heterogeneous African tertiary environment. This implies that institutions are found to be at different levels of readiness for implementing and ensuring quality in the intended online teacher education study programme. 
Therefore, a proposed Quality Assurance Framework should be responsive to the inputs and needs of all the partner institutions as well as the AVU. Since the contexts, needs and circumstances at the different partner institutions are not homogenous, a Quality Assurance Framework is to be viewed and implemented as a descriptive document that is, however, not prescriptive in nature. It is, therefore, necessary to acknowledge the reality that a 'one-size-fits-all' approach will not promote the sought after quality in the multi-country teacher education study programme. Implementing a Quality Assurance Framework should not be an all or nothing position. As Fullan $(1999,46)$ noted, a key feature of implementation should be the presentation of next steps. In the light of next steps it then becomes important to consider a 'zone of feasible implementation' in analogy to Vygotsky's theory of a 'zone of feasible development' (Rogan and Grayson 2003, 118). Each institution should have an opportunity to talk back at a prospective quality assurance framework for the teacher education qualification. This implies they have to define their own next steps for quality improvement. The ten-tiered implementation framework may pave the way for the planning of realistic next steps at each institution to assure quality. It suggests the presence of appropriate and do-able next steps that ensure an institution can actually set their own priorities and timelines towards the development of quality assurance mechanisms. It should also be noted that the higher level practices are not superior to the practices described on the lower levels. The framework does not imply progressing from one level to another. Rather, the higher levels are inclusive of lower ones. All practices described in the ten-tiered framework have merit in ensuring quality. Self-paced planning towards quality assurance, I contend, will not threaten an institution but will empower it towards ownership and inculcation of quality milestones.

In summary, funders, sceptics, supporters, managers and implementers of ODeL environments are aware of the overwhelming challenges and await measures of accountability and quality assurance, to take teacher education to the next level in Africa. Through implementing a differentiated Quality Assurance Framework informed by the ten-tiered differentiated findings framework, the AVU and its partners may be instrumental in building a reflexive and emancipating discourse, for the development of an authentic and indigenous theory and practice of quality assurance in African higher education.

\section{REFERENCES}

Adekanmbi, G. 2007. Current trends in quality considerations for tertiary distance education provisions in Africa. Presented at the South African Association for research and Development in Higher Education International Conference. Groenkloof: University of Pretoria.

Alderman, G. and R. Brown. 2005. Can quality assurance survive the market? Accreditation and audit at the crossroads. Higher Education Quarterly 59 (4): 313-328. 
Binns, F. and A. Otto. 2006. Quality assurance in open distance education - Towards a culture of quality: A case study from the Kyambogo University, Uganda. In Perspectives on distance education: Towards a culture of quality, eds. B. N. Koul and A. Kanwar. Commonwealth of Learning: Vancouver.

Dzvimbo, K. P. and C. W. Kariuki. 2006. Quality assurance in the African Virtual University: A case study. In Perspectives on distance education: Towards a culture of quality, eds. B. N. Koul and A. Kanwar. Commonwealth of Learning: Vancouver.

Fullan, M. 1999. Change forces: The sequal. London: Falmer.

Gouws, A. and Y. Waghid. 2007. Higher education quality assurance in South Africa: accreditation in perspective. South African Journal of Higher Education 20 (6): 751-761.

Graham, K. and J. Tierney. 2005. Improving teacher education through human resource development at ITEK. Midterm review of Nuffield Foundation Commonwealth Programme 2001-2005. Oxford: Nuffield Foundation.

Hattingh, A. 2007. Quality assurance framework for the Teacher Education Programme (Mathematics, Science and ICT) in Africa. The Nairobi Declaration. Teacher Education Advisory Committee, African Virtual University, Nairobi 4-5 April 2007, Kenya.

Higher Education Act of the Republic of South Africa, No. 101 of 1997. As amended by Act 55 of 1999 and Act 54 of 2000. South Africa: Pretoria.

Mostert, J. W. 2006. The challenges for an African DE learner - a distance educator's perspective. South African Journal of Higher Education 20 (3): 501-513.

Robinson, B. 1993. Quality, relevance and effectiveness in distance education, Unit 11. In Course 2, The Development of Distance Education. MA/Diploma in Distance Education. Cambridge: IEC/University of London.

Rogan, J. M. and D. Grayson. 2003. Towards a theory of curriculum implementation with particular reference to Science Education in developing countries. International Journal of Science Education 25 (1): 1171-1204.

Segers, M. and F. Dochy. 1996. Quality assurance in higher education: Theoretical considerations and empirical evidence. Studies in Educational Evaluation 22 (2): 115-137.

Teacher Education Advisory Committee. 2007. Terms of reference for the Teacher Education Advisory Committee. African Virtual University, 27-28 March, Nairobi, Kenya. 